\title{
Colonial opacity variations among the choleragenic vibrios
}

\author{
Richard A. Finkelstein, ${ }^{1}$ Mary Boesman-Finkelstein, ${ }^{1}$ Dilip K. Sengupta, ${ }^{1}$ \\ William J. Page, ${ }^{2}$ C. Michael Stanley ${ }^{3}$ and Thomas E. Phillips ${ }^{3}$
}

Author for correspondence: Richard A. Finkelstein. Tel: +1 573882 4117. Fax: + 15738847885. e-mail: mmiflab@mizzou1.missouri.edu

1 Department of Molecular Microbiology and Immunology, School of Medicine, University of Missouri, Columbia, MO 65212, USA

2 Department of Biological Sciences, University of Alberta, Edmonton, Alberta, Canada T6G 2E9

3 Division of Biological Sciences, University of Missouri, Columbia, MO 65211, USA

\begin{abstract}
Cultures of Vibrio cholerae 01, biotype El Tor, from the current epidemic of cholera in the Western Hemisphere, and of the new $V$. cholerae serogroup 0139, from the current outbreak in India and Bangladesh, revealed marked colonial heterogeneity when received by the authors. By comparison with reference colony types, using a stereoscope and transmitted oblique illumination, colonies of approximately 10 different degrees of opacity could be distinguished. In contrast, strains freshly isolated from patients and rapidly and carefully preserved were more homogeneous although still differentiable by this technique. These (and older) observations prompted the questions: (1) why is a $V$. cholerae colony opaque or translucent? and (2) what benefit is it to the vibrios to vary their colonial appearance? The observed changes in colonial opacity, which are reversible, are sometimes (rarely) accompanied by changes in virulence for infant rabbits and, more frequently, by other phenotypic variations including the ability to produce poly- $\beta$-hydroxybutyrate inclusion bodies on glycerol-containing medium, the degree of encapsulation in 0139 , changes in outer-membrane proteins, alteration in lipopolysaccharide structure, changes in expression of glycolytic pathways, and differences in ability to survive under adverse conditions. Colonial variations in choleragenic vibrios are phenotypically multifactorial. The genetic mechanisms(s) underlying the observed phenotypic changes remain to be defined.
\end{abstract}

Keywords: Vibrio cholerae, colonial variation, opacity, poly- $\beta$-hydroxybutyrate (PHB), capsules

\section{INTRODUCTION}

Cholera vibrios have long been known to be mercurial in their ability to exhibit variations in colonial morphology. Robert Koch was the first to observe that the colonial appearance of cholera vibrios was distinct from that of other bacterial species (Pollitzer, 1959, p. 125). Soon thereafter, Kolle and Gotschlich (Pollitzer, 1959, pp. 452-456), and subsequently others, noted that vibrio subcultures contained opaque $(\mathrm{O})$ and translucent $(\mathrm{T})$ colonial variants. Lankford (1960) observed that nearly all colonies of classical biotype Vibrio cholerae on primary culture from patients in Calcutta, India, in 1953, and in Bangkok, Thailand, in 1958, were of a single characteristic 'typically opaque and striated' colony type, whereas most stock cultures of $V$. cholerae

Abbreviations: LOS, lipooligosaccharide; MR, methyl red; OU, opacity unit; PHB, poly- $\beta$-hydroxybutyrate; VP, Voges-Proskauer. were mixtures of colony types or pure types differing from each other. Colonies which deviated from the 'typical' colony type usually had reduced virulence for 13-d-old chicken embryos (Lankford, 1960; Gardner et al., 1964). The apparent homogeneity of fresh isolates has also been the author's (R.A.F.'s) experience during cholera epidemics of El Tor and classical biotypes in the Philippines, India, Vietnam and Thailand during the period from 1961 to 1967 . In 1966, it was noted (Finkelstein, 1966) that stock cultures of El Tor biotype $V$. cholerae sent from Tehran, Iran, yielded $\mathrm{O}$ and $\mathrm{T}$ colonies, of which the $\mathrm{T}$ types were haemolytic and the Os were not. This was at a time when the El Tor vibrios, the cause of the present seventh great cholera pandemic, were losing their haemolytic ability which was, originally, the sine qua non for their differentiation from the classical biotype. Subsequently, it was observed (Holmes et al., 1975) that the virulent hypertoxinogenic $T$ colony type of El Tor biotype Ogawa serotype strain 3083 
spontaneously and reversibly produced $O$ colonial variants which were Tox $^{-}$and avirulent. These observations have been repeated with that strain in our laboratory many times subsequently (M. BoesmanFinkelstein, unpublished observations), although it was noted recently (Finkelstein et al., 1992) that other opacity/translucency changes were not accompanied by changes in virulence and toxinogenicity either in strain 3083 or in strains recently received from Peru. Cultures of the new V. cholerae serogroup O139 (syn. Bengal) from the current outbreak in India and Bangladesh (Albert, 1994), recently received and examined in our laboratory, were found to be markedly heterogeneous. We therefore decided to address the questions of the mechanisms and reasons for colonial variation among the choleragenic vibrios.

In other micro-organisms (Anderson \& Dawes, 1990; Johnson et al., 1992; Mills et al., 1992; Page \& Knosp, 1989; Poolman et al., 1985; Swanson et al., 1992; Weiser, 1993; Weiser et al., 1994; Wise et al., 1992; Yoshida et al., 1985), colonial variations such as those noted above have been associated with a variety of properties including changes in content of poly- $\beta$ hydroxybutyrate (PHB), changes in outer-membrane proteins, lipoproteins, lipopolysaccharides (LPS) or lipooligosaccharides, capsulation or piliation, which may or may not be associated with changes in virulence in pathogenic species. In a recent study of Haemophilus influenzae by Weiser et al. (1995), in addition to differences in LPS structure and encapsulation observed previously between opaque and less opaque colonial phenotypes, a novel $47 \mathrm{kDa}$ opacity-associated protein, OapA, was identified which was associated with the translucent phenotype and ability to colonize the nasopharynx (of mice) but not with virulence by intraperitoneal challenge.

Although relative little is known about these phenomena in $V$. cholerae, Lankford (1960) had alluded to a correlation between opacity and the presence of sudanophilic lipid globules within the cells and, more recently, strains of V. cholerae $\mathrm{O} 139$ were reported (Johnson et al., 1994; Weintraub et al., 1994) to have a polysaccharide capsule which correlated with opacity.

Portions of the work described here have been presented at the General Meeting of the American Society for Microbiology, 23-27 May 1994 (Las Vegas, NV), and at the US-Japan Cooperative Medical Science Program, 31st Joint Conference on Cholera and Related Diarrheal Diseases, Kiawah Island (Charleston), South Carolina, 1-3 December 1995.

\section{METHODS}

Vibrio strains, media, and procedures. $V$. cholerae $\mathrm{O} 1$ strains of El Tor and classical biotypes and Inaba and Ogawa serotypes were primarily from our own culture collection maintained by lyophilization since shortly after isolation or receipt and, as working stocks, by storage at $-70^{\circ} \mathrm{C}$ in tryptic soy broth with $20 \%(\mathrm{v} / \mathrm{v})$ glycerol. Serogroup O139 cultures from the current outbreak in India and Bangladesh were provided by G. Balakrish Nair and M. John Albert, respectively (Shimada et al., 1993). M. John Albert also provided strains, isolated in 1994 and 1995, which were lyophilized from the progeny of isolated single colonies from the primary culture of the patients' specimens (stool or rectal swab) on TCBS agar. Y. Takeda provided strain O139 M045 and unabsorbed rabbit antisera to it (Shimada et al., 1993).

Routinely, Petri dishes, $85 \mathrm{~mm}$ diameter, containing $16 \mathrm{ml}$ meat extract agar (MEA; $0.3 \%$ Bacto beef extract, $1.0 \%$ Bacto-peptone, $0.5 \% \mathrm{NaCl}$ and $2 \%$ Difco agar) or modified '2-1 agar' (Henry, 1933; Braun, 1953) - the medium used previously by Lankford (1960) - a formulation similar to MEA but containing $0.5 \%$ Bacto beef extract and $0.5 \%$ glycerol, were streaked for semi-confluent growth and incubated at $37^{\circ} \mathrm{C}$ for $16 \mathrm{~h}$, harvested with $10 \mathrm{ml}$ sterile $0.1 \%$ peptone saline and decimally serially diluted. Ten microlitre droplets of a $1: 2$ dilution of the $10^{-6}$ dilution were applied to previously dried duplicate Petri dishes and allowed to dry in so that no visible surface moisture remained before incubation. This procedure may be expected to yield approximately 25 isolated colonies in a circumscribed area about $1 \mathrm{~cm}$ in diameter. Standard reference strains arbitrarily defined from previous experience as representing $2,4,6$ and 8 opacity units (OU) were deposited in a square pattern in the centre of the Petri dish and unknown cultures, treated similarly, were dropped around the periphery (see Fig. 1). Observations were usually made after $16-18 \mathrm{~h}$ incubation at $37^{\circ} \mathrm{C}$ using a stereoscope and transmitted oblique illumination according to a modification (Finkelstein \& Punyashthiti, 1967) of the technique of Henry (Braun, 1953). For evaluation of variability, multiple observers were given brief instructions and asked to grade the opacity of the unknowns by comparison with the reference strains. Means and standard errors were then calculated. One O139 strain, MDO-12 from Madurai, India, which, when received by us, yielded three colony types of increasing opacity, MDO-12-A, MDO-12-B, and MDO-12$\mathrm{C}$, was selected for more extensive study. Strain MDO-12-C forms the most opaque $V$. cholerae colonies we have seen $(\mathrm{OU}=10)$.

Image analysis and processing. A stereoscope equipped with a black-and-white CCD (charge-coupled device) camera was used to capture digital images of individual colonies growing on agar plates. Along with each colony image, an image of an adjacent region of agar without a bacterial colony was acquired to serve as a measure of background density. The Image1 AT (Universal Imaging) image analysis system was used to subtract the background (agar only) density from the colony's image and quantify the area brightness (average pixel brightness values) of the colonies. A CCD equipped with a macroscopic lens was used to capture the images of whole plates used as illustrations in this report. To accentuate the differences in grey-scale opacity, software (Adobe Photoshop) was used to create an arbitrary colour look-up table to pseudo-colour the digitized images.

Transmission electron microscopy. Bacteria growing as isolated colonies were overlaid with molten $2 \%$ agar in PBS and immediately chilled on a bed of ice. The plate was then covered with $10 \mathrm{ml}$ paraformaldehyde/glutaraldehyde fixative (PFG; $2 \%$ freshly depolymerized paraformaldehyde, $2.5 \%$ glutaraldehyde, $70 \mathrm{mM} \mathrm{NaCl}, 30 \mathrm{mM}$ HEPES, $2 \mathrm{mM} \mathrm{CaCl}$, $\mathrm{pH} 7.4$ ) for $3 \mathrm{~h}$ at $4^{\circ} \mathrm{C}$. A razor blade was then used to cut out thin $(1 \times 1 \times 2 \mathrm{~mm})$ rectangles of bacterial colonies sandwiched between the two agar layers. Following overnight fixation in fresh PFG, the samples were rinsed eight times in HEPES washing buffer (HWB; $70 \mathrm{mM} \mathrm{NaCl}, 30 \mathrm{mM}$ HEPES, 
$\mathrm{pH} 7 \cdot 4$ ) over the course of $2 \mathrm{~h}$. The samples were post-fixed in $1 \%$ osmium tetroxide in HWB for $4 \mathrm{~h}$ at room temperature, rinsed six times with deionized water, and en bloc stained in $0.5 \%$ uranyl acetate for $1 \mathrm{~h}$. Following extensive rinsing, the samples were dehydrated with a series of ethanol and propylene oxide and embedded in EmBed812 epoxy resin. Thin sections were stained with uranyl acetate for $10 \mathrm{~min}$ and lead citrate for $3 \mathrm{~min}$ before examination in a transmission electron microscope.

PHB staining. In some experiments, $0.5 \%$ malachite green hydrochloride was added to the PFG fixative to selectively stain the PHB granules (Kushnaryov et al., 1980; Sun et al., 1994). All other steps followed our routine fixation and embedding procedure.

PHB analysis. PHB content of the bacterial cells was analysed by HPLC after acid hydrolysis to crotonic acid as described by Karr et al. (1983). Wet cells, ranging from 100 to $200 \mathrm{mg}$, harvested from semi-confluently streaked Petri dishes, were digested in $1 \mathrm{ml}$ concentrated sulfuric acid at $90^{\circ} \mathrm{C}$ for $30 \mathrm{~min}$ and then cooled on ice. (Lyophilized or oven-dried, $80^{\circ} \mathrm{C}$ overnight, cells were used for dry weight determinations.) Before analysis by HPLC, digested samples were appropriately diluted with $7 \mathrm{mM} \mathrm{H}_{2} \mathrm{SO}_{4}$ and filtered through a $0.45 \mu \mathrm{m}$ cellulose acetate filter (Costar Europe) to remove particulate material. Samples $(50 \mu \mathrm{l})$ were then injected into a fast acid analysis column $(100 \times 7.8 \mathrm{~mm}$; Bio-Rad) and eluted with $7 \mathrm{mM} \mathrm{H}_{2} \mathrm{SO}_{4}$ at a flow rate of $0.5 \mathrm{ml} \mathrm{min}^{-1}$. Absorbance of crotonic acid was then measured at $214 \mathrm{~nm}$ (Millipore Waters Lambda-Max model 481, LC spectrophotometer). The amount of crotonic acid produced was determined from the area of the peak of a known crotonic acid standard. Finally, on the basis of stoichiometry of the chemical reaction, the amount of crotonic acid produced was expressed in terms of PHB. It should be noted that PHB values may fluctuate depending on the age of the culture, confluency of the bacterial growth, and variations in processing.

$\mathrm{PHB}$ and longer-chain $\beta$-hydroxyalkanoates, especially hydroxyvalerate, were determined using washed and then dried (lyophilized) bacteria by the method of Page et al. (1992), except that the polymer was not purified before methanolysis, but instead, was extracted from the cells with chloroform. Parallel studies with Azotobacter vinelandii cells indicated that this method extracted approximately $50 \%$ of the polymer.

Capsule staining. Capsules were demonstrated by staining with polycationic ferritin (Johnson et al., 1992). Agar-grown bacteria were flooded with $5 \%$ glutaraldehyde in HWB, $\mathrm{pH} 7.0$, for $90 \mathrm{~min}$ at room temperature. The bacteria were then resuspended in the same fixative using gentle trituration with a Pasteur pipette and placed in a $15 \mathrm{ml}$ centrifuge tube for an additional $30 \mathrm{~min}$ of fixation. After gentle centrifugation and resuspension in HWB three times to remove the fixative, the bacteria were exposed to polycationic ferritin $\left(1 \mathrm{mg} \mathrm{ml}^{-1}\right.$; Sigma) in HWB for $2 \mathrm{~h}$ at room temperature and then washed in the same buffer three times. The final pellet was resuspended in $0.3 \mathrm{ml}$ ice-cold buffer and mixed with $0.5 \mathrm{ml} 2 \%$ agar in HWB at $42^{\circ} \mathrm{C}$ in a $15 \mathrm{~mm}$ wide well of a 24 -cell tissue culture tray sitting on ice. The fixed agar disk was removed, diced into $1 \times 2 \times 2 \mathrm{~mm}$ rectangles and fixed in $1 \%$ osmium tetroxide in HEPES buffer overnight. Following washing, the agar pieces were dehydrated and embedded in epoxy resin as described above. Thin sections were stained with uranyl acetate for $10 \mathrm{~min}$ and lead citrate for $3 \mathrm{~min}$ before examination in a transmission electron microscope.
Outer membrane preparation. Outer membranes were prepared from different $V$. cholerae strains by treatment with sarcosine as described by Filip et al. (1973) with minor modifications. Bacteria were first deflagellated by homogenization and then disrupted by an ultrasonic disintegrator at $4{ }^{\circ} \mathrm{C}$. Unlysed cells were then removed by low-speed centrifugation $(8000 \mathrm{~g}, 10 \mathrm{~min})$ and the crude envelope fraction was collected from the supernatant by ultracentrifugation $(100000 \mathrm{~g}, 1 \mathrm{~h})$. The pellet containing the crude envelope fraction was treated with $0.5 \%(\mathrm{w} / \mathrm{v}$ ) Sarkosyl (Sigma) solution to selectively solubilize the inner membrane part. The insoluble outer membrane fraction was finally recovered as pellet by ultracentrifugation $(100000 \mathrm{~g}, 1 \mathrm{~h})$ at $4^{\circ} \mathrm{C}$. The pellet was washed once with Sarkosyl $(0.5 \%)$ solution and once with distilled water and finally stored at $-20^{\circ} \mathrm{C}$ until used. Protein content of outer-membrane preparations was determined by the method of Markwell et al. (1978) with bovine serum albumin as a standard.

LPS preparation. LPS was prepared from whole-cell $V$. cholerae lysates by the proteinase $\mathrm{K}$ digestion method as described by Kimura \& Hansen (1986). Bacteria were first lysed in $0.5 \mathrm{vol}$. concentrated digestion buffer $[0.1875 \mathrm{M}$ Tris $/ \mathrm{HCl}, \mathrm{pH} 6.8 ; 6 \%$ (w/v) SDS; $30 \%$ glycerol] at $100{ }^{\circ} \mathrm{C}$ for $5 \mathrm{~min}$. The bacterial lysates were then diluted fourfold with LPS digestion buffer $(0 \cdot 0625 \mathrm{M}$ Tris $/ \mathrm{HCl}, \mathrm{pH} 6 \cdot 8 ; 0 \cdot 1 \%$ SDS; $10 \%$ glycerol and $0.005 \%$ bromophenol blue) and deproteinized by proteinase K (Sigma).

SDSPAGE. Samples were analysed on SDS-polyacrylamide gels $[12.5 \%(\mathrm{w} / \mathrm{v})$ for protein and $15 \%(\mathrm{w} / \mathrm{v})$ for LPS] using $4.5 \%(\mathrm{w} / \mathrm{v})$ stacking gels on top (Laemmli, 1970). Electrophoresis was carried out at room temperature at constant voltage $(120 \mathrm{~V})$ until the tracking dye reached a point $1 \mathrm{~cm}$ above the bottom of the separating gel. After electrophoresis, proteins and LPS were visualized by the silver staining methods of Oakley et al. (1980) and Tsai \& Frasch (1982), respectively.

Frequency of colonial variation. The frequency of colonial variation was determined for exponential-phase cultures of single-colony isolates of strains MDO-12-A, MDO-12-C, and 3083-O in tryptic soy broth using the formula : frequency = [(no. of variants)/(total viable cell count)]/no. of generations.

Survival under adverse conditions. A preliminary effort was made to evaluate the relationship, if any, of colonial opacity to survival under adverse conditions. Previous experience (Finkelstein, 1962) had demonstrated that cholera vibrios tend to die off relatively rapidly when suspended in normal saline but were protected by a concentration of peptone, $0.1 \%$, which was not sufficient to support multiplication. Accordingly, suspensions of approximately $10^{6}$ viable cells $\mathrm{ml}^{-1}$ were incubated in normal saline for $24 \mathrm{~h}$ at 4,25 and $37^{\circ} \mathrm{C}$, and dilution-plated to determine viability.

\section{RESULTS}

\section{Stereoscopic observations with transmitted oblique illumination}

To begin the present study, we examined a variety of isolated colonies of laboratory strains of $V$. cholerae $\mathrm{O} 1$ and $\mathrm{O} 139$ grown on meat extract agar (MEA) using a stereoscope and transmitted oblique illumination as described previously (Finkelstein \& Punyashthiti, 1967). We could easily classify unknown cultures into approximately 10 different degrees of opacity by comparison 

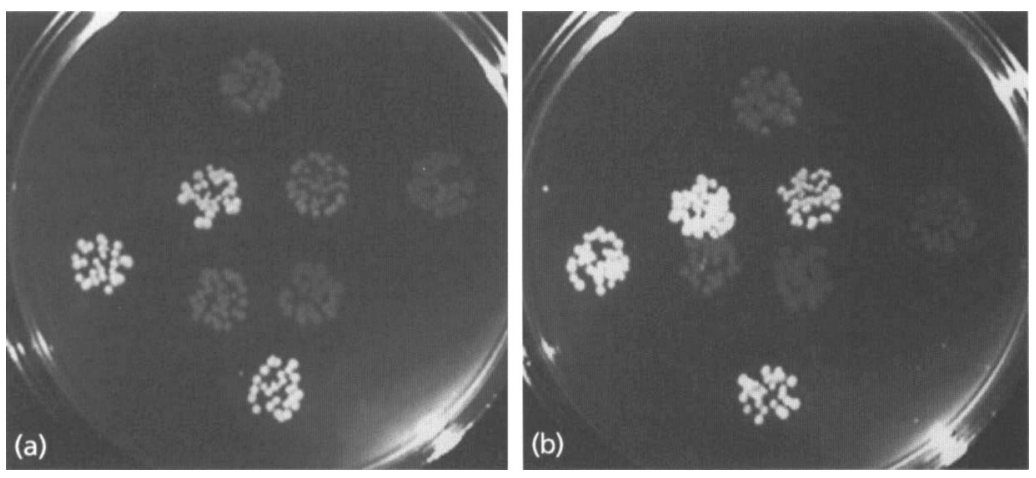

\begin{abstract}
Fig. 1. Visual images of $V$. cholerae 0139 colonies growing on nutrient agar supplemented with either $0 \%$ (a) or $0.5 \%$ glycerol (b). The centre colonies, clockwise from top left, are four reference strains: $1852 \mathrm{O}(\mathrm{OU}=8), 4450 \mathrm{~T}(\mathrm{OU}=6), 1855 \mathrm{~T}$ $(O U=2)$ and $1838 \mathrm{~T} \quad(O U=4)$. The peripheral colonies are, clockwise from the top: $\mathrm{MDO}-12-\mathrm{B}(\mathrm{OU}=4)$, MDO-12-A $(\mathrm{OU}=$ 2), MO 45 (ranked at $O U=7$ with a few more translucent colonies) and MDO-12-C $(\mathrm{OU}=10)$.
\end{abstract}

with reference cultures (Fig. 1a). Individuals with no previous experience could quantify the opacity of cultures with a high degree of reproducibility. However, whereas we have previously (Finkelstein \& Gomez, 1963; Finkelstein \& Punyashthiti, 1967) regarded freshly isolated wild-type $V$. cholerae as being extremely translucent when compared with colonies of other intestinal microflora on MEA, Lankford (1960) regarded the $V$. cholerae colonies he isolated in Calcutta and in Bangkok as 'typical opaque striated' and noted that a small proportion of less opaque or even translucent colonies sometimes appeared transiently in the primary cultures. In static or serially transferred cultures (Lankford, 1960), the population became progressively less opaque and more variable. One significant difference between Lankford's and our work was that Lankford used '2-1 agar', a nutrient agar medium of similar composition to MEA but which had a higher concentration of beef extract, $0.5 \%$, and also contained $2 \%$ glycerol and 1\% glucose (Henry, 1933; Braun, 1953). Using the same reference cultures, a series of experiments (results not shown) revealed that it was the glycerol in Lankford's medium that affected the opacity of the colonies. Although the relative order of opacity of the reference colonies was maintained, the differences between the more translucent and the more opaque colonies were enhanced on glycerol-containing medium (compare Fig. 1a and Fig. 1b). Furthermore, 0.5\% glycerol (Fig. 1b) was found to be optimal in this regard and therefore this formulation was used in our subsequent studies.

The visual observations were highly reproducible to different individuals. Average transmitted light intensities, determined with the Image- 1 analysis system, were found to be proportional to visual observations, but not always in perfect agreement, suggesting that other optical qualities (e.g. tint and opalescence) that could be discriminated by the human eye but not by image analysis were involved.

\section{PHB}

Because sudanophilic lipid had earlier been implicated in opacity of $V$. cholerae (Lankford, 1960) and PHB had been observed in V. cholerae and other vibrios (Hood et al., 1986; Sun et al., 1994; Tamura et al., 1968) and associated with opacity in other bacteria (Anderson \& Dawes, 1990; Page \& Knosp, 1989), we undertook to examine the PHB content of various strains and colonial variants of $V$. cholerae using electron microscopy and biochemical analysis.

Electron microscopy. When MDO-12-C was grown on $0.5 \%$ glycerol-containing medium for $12 \mathrm{~h}$, cross-sectional profiles of bacteria were frequently observed to contain one to four electron-dense membrane-bound granules which were stained by the PHB-specific dye malachite green. Opaque bacteria also contained 10-20 electron-translucent inclusion bodies (Fig. 2a).

Both the malachite-green-stainable granules and electron-translucent granules were still present in individual colonies of MDO-12-C grown for $24 \mathrm{~h}$ (Fig. 2b) although confluent lawns of MDO-12-C were found to contain neither type of inclusion body after $24 \mathrm{~h}$ (not shown). At $36 \mathrm{~h}$, individual colonies of MDO-12-C had reduced content of both types of inclusion body (Fig. 2c). The granules were apparently consumed under crowded conditions and with ageing of the culture. When MDO-12-C was grown without glycerol for $12 \mathrm{~h}$, only occasional examples of bacterial cross-sections contained a malachite-green-stained granule; these granules were smaller and more electron dense than ones observed in colonies grown on $0.5 \%$ glycerol (compare Fig. 2d with Fig. 2a). In colonies of the translucent colony type MDO-12-A grown on $0.5 \%$ glycerol for $12 \mathrm{~h}$, there was no evidence of either the malachite-green-stained granules or the electron-translucent granules (Fig. 2e). Bacteria in individual colonies of the intermediate opacity strain MDO-12-B occasionally contained a small densely stained malachite-green-stained granule but few, if any, of the electron-translucent granules (Fig. 2f). Interestingly, in MDO-12-B, the malachite-green-stained granules were frequently located along the periphery of the cell as opposed to the more centrally located granules of MDO12-C. Occasional examples of extracellular malachitegreen-stained granules were found in the MDO-12-B colonies but not in MDO-12-A or MDO-12-C colonies.

Biochemical analysis. As shown in Table 1, the PHB 

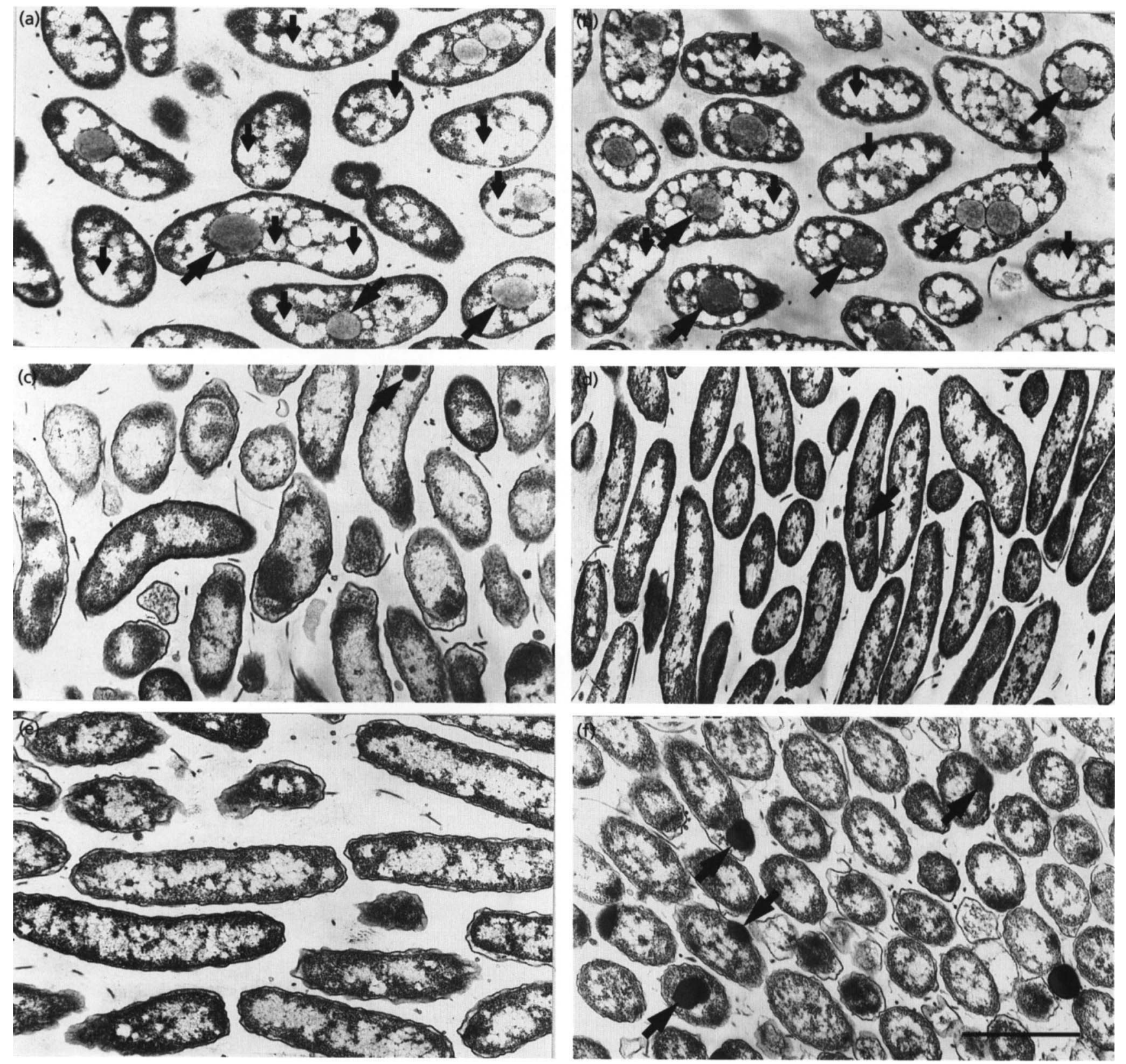

Fig. 2. Malachite-green-stained transmission electron micrographs of: (a) MDO-12-C, $12 \mathrm{~h}+0.5 \%$ glycerol; (b) MDO-12-C, $24 \mathrm{~h}+0.5 \%$ glycerol; (c) MDO-12-C, $36 \mathrm{~h}+0.5 \%$ glycerol; (d) MDO-12-C, $12 \mathrm{~h}+0 \%$ glycerol; (e) MDO-12-A, $12 \mathrm{~h}+0.5 \%$ glycerol; (f) MDO-12-B, $12 \mathrm{~h}+0.5 \%$ glycerol. Large arrows, malachite-green-stained granules; small arrows, electrontranslucent inclusions. Bar, $1 \mu \mathrm{m}$.

contents of translucent variants (MDO-12-A and MDO12-B) of strain MDO-12 were low, even in the presence of glycerol, whereas the $\mathrm{PHB}$ content of opaque variant MDO-12-C peaked sharply at concentrations of $0.5-1 \cdot 0 \%$ glycerol to levels more than 10 times those of the translucent variants on $0.5 \%$ glycerol. Analyses of a large number of fresh isolates, carefully preserved, of both $\mathrm{O} 1$ and $\mathrm{O} 139$ serogroups on glycerol medium revealed (Table 2, Fig. 3) a strong and significant correlation between opacity and the ability to produce PHB.
It is interesting to note that the freshly isolated O139 strains fell into three opacity groups, with OUs ranging from 8.1 to $8 \cdot 4,7 \cdot 4$ to $7 \cdot 6$, and 6.4 to 6.9 (Table $2 \mathrm{a}$ ), which would not have been recognized as different if they had been observed on different plates and not compared with reference colonies. Strain AJ 27-439-T was from a translucent sector found in the growth of its parent strain AJ 27-439, which had 2.6-fold higher PHB content. Most of the O1 El Tor Ogawa strains included in Fig. 3 were less opaque and produced less PHB than the O139 strains and they also seemed to fall into three 
Table 1. PHB content of variants of $V$. cholerae 0139 (syn. Bengal) strain MDO-12 grown for $12 \mathrm{~h}$ on nutrient agar with varying glycerol concentrations

\begin{tabular}{|llr|}
\hline Variant & $\begin{array}{c}\text { Glycerol } \\
(\%)\end{array}$ & PHB $^{*}$ \\
\hline MDO-12-A & 0.5 & $2.5 \dagger$ \\
MDO-12-B & 0.5 & $4.0 \dagger$ \\
MDO-12-C & 0.0 & $3.6 \ddagger$ \\
& 0.25 & $5.4 \ddagger$ \\
& 0.5 & $26.4 \$$ \\
& 1.0 & $26.9 \ddagger$ \\
& 2.0 & $18.3 \ddagger$ \\
\hline
\end{tabular}

* Determined as crotonic acid (Karr et al., 1983); mg (g dry wt) ${ }^{-1}$.

† Result of two identical independent determinations.

$\ddagger$ Result of a single determination.

$\$$ Mean of three independent determinations (range 20.0-32.5).

groups, OU $6 \cdot 1-6 \cdot 7,5 \cdot 2-5 \cdot 6$ and $4 \cdot 3-4 \cdot 7$ (Table $2 b$ ). When similar studies were performed with a random collection of 34 older stock cultures and colonial variants (Table 3), the correlation, although significant, was not as striking $\left(r^{2}=0.41\right.$; data not shown). Although the sample size is small, the older classical biotype O1 isolates seem to have higher PHB levels. As a general rule, strains with $\mathrm{OU} \leqslant 5$ had significantly lower PHB content than strains with $\mathrm{OU}>5$ on glycerol-containing medium (Table 4).

Four strains, CA-411, CA-172, CA-174 and CA-401, from Lankford's original collection of classical biotype V. cholerae isolated in Calcutta in 1953 (Lankford, 1960) which had been regarded by him as 'typical opaque', and preserved by lyophilization since that time, were scored between 5.2 and 5.6 OUs and had PHB contents ranging from $31 \cdot 2$ to $47 \cdot 2 \mathrm{mg} \mathrm{g}^{-1}$ (Table 3 ). Strain 3083$T$, a variant selected from an El Tor biotype culture isolated (by R.A.F.) in Vietnam in 1963 and preserved carefully since then, formed the most translucent colonies we have seen $(O U=1)$ and was virulent and toxinogenic whereas a more opaque $(\mathrm{OU}=5 \cdot 3)$ colony type isolated from the same strain was avirulent (Holmes et al., 1975). On glycerol medium, these two had PHB contents of 9.3 and $17.6 \mathrm{mg} \mathrm{g}^{-1}$, respectively. It is interesting that these two can be differentiated by the naked eye and, before the advent of the $\mathrm{O} 139$ isolates and our use of glycerol medium, we had regarded 3083$\mathrm{O}$ as unusually opaque. It appears that the ability to produce $\mathrm{PHB}$, while related to opacity in the absence of glycerol and contributory to it in its presence, is not directly or totally responsible for opacity - especially when one considers the MDO-12 series, cited above, which were originally graded by their opacity on glycerol-free medium in which their PHB contents were low. However, the addition of glycerol markedly expands the range of opacity which is observed.

Polyhydroxyalkanoate analyses by the method of Page
Table 2. Opacity and PHB content of 'single-passage' $V$. cholerae 0139 (a) and 01 strains (b) from Bangladesh

\begin{tabular}{|c|c|c|}
\hline Strain & $\begin{array}{c}\text { Opacity } \\
(\mathrm{OU})^{*}\end{array}$ & PHB + \\
\hline \multicolumn{3}{|c|}{ (a) 0139 strains } \\
\hline AJ $27-513$ & $8.4(0.24)$ & $37 \cdot 1$ \\
\hline-495 & $8.4(0.24)$ & $33 \cdot 2$ \\
\hline-493 & $8 \cdot 2(0 \cdot 20)$ & $29 \cdot 5$ \\
\hline-448 & $8.4(0.24)$ & $31 \cdot 2$ \\
\hline-426 & $8 \cdot 2(0 \cdot 20)$ & $29 \cdot 5$ \\
\hline-425 & $8 \cdot 4(0 \cdot 24)$ & $21 \cdot 7$ \\
\hline $150649 \ddagger$ & $8 \cdot 1(0 \cdot 20)$ & $34 \cdot 0$ \\
\hline AJ $27-514$ & $7 \cdot 6(0 \cdot 24)$ & $26 \cdot 8$ \\
\hline-439 & $7 \cdot 4(0 \cdot 24)$ & $22 \cdot 7$ \\
\hline $1433569 \neq$ & $7 \cdot 6(0 \cdot 16)$ & $25 \cdot 9$ \\
\hline AJ $27-404$ & $6.5(0.32)$ & $18 \cdot 1$ \\
\hline-370 & $6.4(0.24)$ & $17 \cdot 1$ \\
\hline $150648 \ddagger$ & $6 \cdot 7(0 \cdot 17)$ & $19 \cdot 2$ \\
\hline $1653 \ddagger$ & $6 \cdot 8(0 \cdot 17)$ & $19 \cdot 1$ \\
\hline $1433574 \ddagger$ & $6.9(0.21)$ & $19 \cdot 4$ \\
\hline AJ 27-439-TS & $5 \cdot 0(0 \cdot 0)$ & $8 \cdot 8$ \\
\hline \multicolumn{3}{|c|}{ (b) O1 strains } \\
\hline $143390 \ddagger$ & $6.7(0.25)$ & $12 \cdot 2$ \\
\hline $150640 \ddagger$ & $6 \cdot 6(0 \cdot 20)$ & $10 \cdot 9$ \\
\hline $150678 \ddagger$ & $6.4(0.23)$ & $10 \cdot 3$ \\
\hline $1718 \neq$ & $6 \cdot 1(0 \cdot 17)$ & $12 \cdot 9$ \\
\hline $1434625 \ddagger$ & $5.6(0.20)$ & $9 \cdot 8$ \\
\hline $150659 \ddagger$ & $5 \cdot 2(0 \cdot 12)$ & $8 \cdot 3$ \\
\hline $1434450 \neq$ & $4 \cdot 7(0 \cdot 25)$ & $2 \cdot 3$ \\
\hline $150668 \ddagger$ & $4.4(0.33)$ & $2 \cdot 3$ \\
\hline $1433875 \neq$ & $4.3(0.33)$ & $2 \cdot 3$ \\
\hline $20492 \ddagger$ & $4.3(0.31)$ & $1 \cdot 9$ \\
\hline
\end{tabular}

"Mean ( \pm s.E.), as determined by five observers, of colonies on glycerol $(0.5 \%)$ medium in comparison with reference opacity standard strains.

†Determined as crotonic acid (Karr et al., 1983); $\mathrm{mg}(\mathrm{g} \mathrm{dry} \text { weight })^{-1}$. Mean of duplicate assays of $18 \mathrm{~h}$ grown bacteria.

$\ddagger$ Isolates from August 1995. Other strains were from October 1994.

SColonial (T) variant of AJ 27-439.

et al. (1992) confirmed that PHB was consumed in older cultures of MDO-12-C. The results also indicated that $V$. cholerae forms a small amount of hydroxyvalerate (HV), most likely in the form of the common copolymer $\mathrm{P}$ (HB-co-HV) in which the HV content is quite low, i.e. approximately 4-5 mol \%. MDO-12-A, the most translucent variant, formed neither PHB nor PHV detectable in this assay.

\section{Capsulation}

Reports of capsulation of Vibrio vulnificus and of non$\mathrm{O} 1 \mathrm{~V}$. cholerae (including O139 strains) and its association with opacity prompted us to examine the 


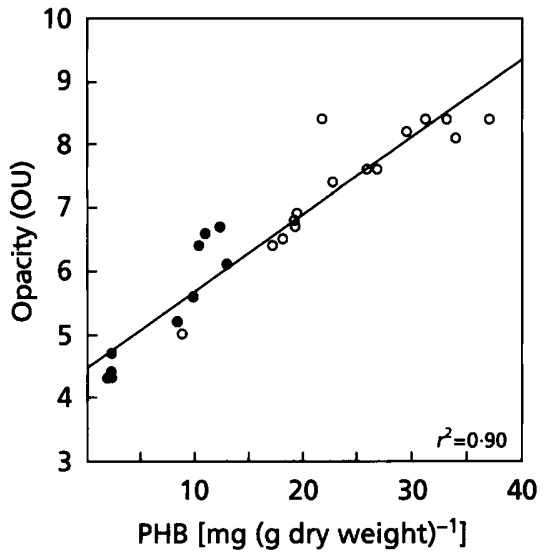

Fig. 3. PHB content of freshly isolated and carefully preserved strains of (O) V. cholerae 0139 and (O) 01 (El Tor Biotype) from Bangladesh.

presence of capsules in the colonial variants of strain MDO-12. The most opaque colony type, MDO-12-C, was heavily encapsulated as revealed by electron microscopy with polycationic ferritin (Fig. 4a): it was surrounded by a thick deposit of cationized ferritin presumably defining the termini of long-chain capsular polysaccharides. Its capsules were much more massive than those reported by others (Johnson et al., 1994; Weintraub et al., 1994). The more translucent strain MDO-12-B (Fig. 4b) had a smaller coat of cationized ferritin closer to the outer membrane which was similar to previous reports. The most translucent strain, MDO12-A, was coated with a thin layer of cationized ferritin lying close to the outer membrane (Fig. 4c). Such a staining pattern is consistent with binding to the noncapsular LPS and the absence of long-chain capsular polysaccharide.

\section{Virulence}

Unlike strains 3083-T and 3083-O described previously (Holmes et al., 1975; M. Boesman-Finkelstein, unpublished results), MDO-12-A and C were both found to be toxinogenic and equally virulent for infant rabbits. Choleragenic scores (Finkelstein et al., 1992), at 24 h, for three infant rabbits per group inoculated intraintestinally with $10^{7}$ live vibrios of MDO-12-A and MDO-12-C, were $7 \cdot 0$ and $6 \cdot 7$, respectively.

\section{Outer-membrane proteins}

Colonial variants of both $\mathrm{O} 139$ and $\mathrm{O} 1$ serogroups also exhibit changes in outer-membrane proteins (OMPs) (Fig. 5a). Translucent strain $3083-\mathrm{T}$ has a $49 \mathrm{kDa}$ OMP (Fig. 5a; compare lanes 1 and 2) which is absent in the more opaque 3083-O. Translucent variants MDO-12-A and $B$ express a $27 \mathrm{kDa}$ OMP which is not present in opaque MDO-12-C (Fig. 5a; compare lanes 4 and 5 with lane 3). We have demonstrated that on switching to and fro between translucent and opaque forms these proteins are lost and regained (unpublished data).

\section{Lipopolysaccharide/lipooligosaccharide}

Changes in LPS structure (Fig. 5b) [or, as the LPS does not exhibit the ladder structure typical of highly polymerized simple sugars, the term lipooligosaccharide (LOS) may be preferable] were also observed in colonial variants of MDO-12. MDO-12-C (Fig. 5b, lane 3) produces a slower-migrating LOS than MDO-12-A and $\mathrm{B}$ (Fig. 5b, lanes 1 and 2), resembling that of $\mathrm{El} \mathrm{Tor}$ biotype strain 3083 (Fig. 5b, lanes 4 and 5). These structures are similar to the multiple electrophoretic forms of the $\mathrm{O} 139$ antigen described earlier (Waldor $e t$ al., 1994).

\section{Methyl red/Voges-Proskauer}

Because of the extremely wide range in opacity observed in colonies from cultures which were sent to us from other areas, the identity of unusually opaque or translucent colonies was confirmed by slide agglutination tests with specific antisera and by biochemical tests used taxonomically. All were confirmed to be as labelled even the extreme variations noted in culture MDO-12. Interestingly, however, whereas-like most El Tor biotype strains-MDO-12-C was Voges-Proskauer (VP) positive and methyl red (MR) negative (i.e. it produced acetyl methyl carbinol and did not utilize the mixed acid fermentation pathway), MDO-12-A and B gave the reverse pattern. That these variants arose from a single strain, i.e. that they are reversible, was demonstrated by testing variants from cultures established from serial passage of single colonies (unpublished observations).

\section{Frequency of colonial variation}

The frequencies of colonial variation determined from exponential-phase cultures of single-colony isolates of strains MDO-12-A, MDO-12-B and 3083-O were determined to be $9 \times 10^{-4}, 4 \times 10^{-4}$ and $1 \times 10^{-3}$ per bacterium per generation, respectively. In broth, variation of cultures grown to stationary phase was more frequent in static than in serially passed cultures, suggesting that accumulation of metabolites or deprivation of nutrients may facilitate enrichment of aberrant colony types. It should be mentioned that the $\mathrm{MR}^{+}$ translucent strains produced very tiny colonies on the original 2-1 agar formulation, which contained 1\% glucose; perhaps, because of their mixed acid fermentation pathway, they were inhibited by acid production in the presence of glucose.

\section{Survival}

Finally, to approach the question of the potential advantage of colonial heterogeneity to $V$. cholerae, representative colony types, harvested at $18 \mathrm{~h}$ from MEA and $0.5 \%$ glycerol agar, were diluted to approximately $10^{6}$ viable cells $\mathrm{ml}^{-1}$ in normal saline incubated 
Table 3. Opacity and PHB content of $V$. cholerae strains and colony types from various sources

\begin{tabular}{|c|c|c|c|c|}
\hline Serovar & Source (year) & Strain & $\begin{array}{c}\text { Opacity } \\
\text { (OU) }\end{array}$ & PHB $\$$ \\
\hline \multirow[t]{17}{*}{ O139 } & Bangladesh ('93) & $1837-\mathrm{T}$ & $7 \cdot 0$ & $25 \cdot 0$ \\
\hline & & $1838-\mathrm{T} \dagger$ & $4 \cdot 0$ & $2 \cdot 3$ \\
\hline & & $-\mathrm{O}$ & $5 \cdot 0$ & $2 \cdot 1$ \\
\hline & & 1841 & $3 \cdot 0$ & $2 \cdot 5$ \\
\hline & & $1852-\mathrm{O}+$ & $8 \cdot 0$ & $22 \cdot 3$ \\
\hline & & $1855-\mathrm{T} t$ & $2 \cdot 0$ & $2 \cdot 1$ \\
\hline & & $-\mathrm{O}$ & $5 \cdot 0$ & $2 \cdot 3$ \\
\hline & & $4450-\mathrm{T} \dagger$ & $6 \cdot 0$ & $38 \cdot 5$ \\
\hline & & $4460-\mathrm{T}$ & $6 \cdot 0$ & $25 \cdot 0$ \\
\hline & & -0 & $9 \cdot 0$ & $23 \cdot 4$ \\
\hline & India ('93) & MDO-12-A & $2 \cdot 0$ & $1 \cdot 8$ \\
\hline & & $-B$ & $4 \cdot 0$ & $2 \cdot 6$ \\
\hline & & $-\mathrm{C}$ & $10 \cdot 0$ & $37 \cdot 5$ \\
\hline & & $\mathrm{PO} 2$ & $5 \cdot 0$ & $2 \cdot 1$ \\
\hline & & $\mathrm{MO}-45-\mathrm{T}$ & $5 \cdot 0$ & $1 \cdot 8$ \\
\hline & & AP1-3 & $9 \cdot 0$ & $30 \cdot 9$ \\
\hline & & AP2-2 & $7 \cdot 0$ & $19 \cdot 4$ \\
\hline \multirow[t]{7}{*}{ O1 (ET-O) } & Philippines ('61) & $26-3 \ddagger$ & $6 \cdot 4$ & $23 \cdot 7$ \\
\hline & ('65) & $65-7-5-\mathrm{T}$ & $2 \cdot 4$ & 3.9 \\
\hline & & $-\mathrm{O}$ & $8 \cdot 0$ & $26 \cdot 8$ \\
\hline & Vietnam ('63) & 3064-1‡ & $5 \cdot 8$ & $18 \cdot 8$ \\
\hline & & $3083-\mathrm{T} \ddagger$ & $1 \cdot 0$ & $9 \cdot 3$ \\
\hline & & $-\mathrm{O} \ddagger$ & $5 \cdot 3$ & $17 \cdot 6$ \\
\hline & & $3148-11 \neq$ & $5 \cdot 8$ & $23 \cdot 9$ \\
\hline \multirow[t]{4}{*}{$\mathrm{O} 1$ (ET-I) } & Korat, Thailand ('66) & HP-30‡ & $5 \cdot 3$ & $23 \cdot 0$ \\
\hline & & HP-71‡ & $5 \cdot 2$ & $23 \cdot 1$ \\
\hline & Port Lavaca, TX ('73) & $3242-73$ & $5 \cdot 5$ & $14 \cdot 8$ \\
\hline & ('86) & $2469-\mathrm{T}$ & $4 \cdot 0$ & $1 \cdot 9$ \\
\hline \multirow[t]{4}{*}{$\mathrm{O} 1(\mathrm{C}-\mathrm{O})$} & India ('41) & NIH-41 & $6 \cdot 8$ & $16 \cdot 7$ \\
\hline & ('53) & CA-411‡ & $5 \cdot 6$ & $31 \cdot 2$ \\
\hline & & CA-172‡ & $5 \cdot 5$ & $47 \cdot 2$ \\
\hline & & CA-174‡ & $5 \cdot 5$ & $30 \cdot 4$ \\
\hline \multirow[t]{2}{*}{$\mathrm{O} 1(\mathrm{C}-\mathrm{I})$} & ('41) & NIH-35-A3 & $6 \cdot 4$ & $30 \cdot 9$ \\
\hline & ('53) & CA-401‡ & $5 \cdot 2$ & $32 \cdot 3$ \\
\hline
\end{tabular}

*ET-O, El Tor biotype, Ogawa serotype; ET-I, El Tor biotype, Inaba serotype; C-O, classical biotype, Ogawa serotype; C-I, classical biotype, Inaba serotype.

† Arbitrarily selected to be opacity reference standards for $2,4,6$, and 8 OUs.

$\ddagger$ Lyophilized (by R.A.F.) shortly after isolation from patient. Other strains were maintained in other laboratories and one to three colonies were selected by us when they were streaked in our laboratory. The designations, $\mathrm{T}$ and $\mathrm{O}$, were in reference to each other at that time. OUs were determined subsequently by comparison with reference standard strains.

$\$$ Determined as crotonic acid (mg per g dry weight of bacteria grown for 15-16 h on medium containing $0.5 \%$ glycerol).

for $24 \mathrm{~h}$ at various temperatures (Table 5). In practically every instance, survival for $24 \mathrm{~h}$ was higher with the more opaque variants - in some instances the differences in survival were 10 -fold or more. The opaque encapsulated MDO-12-C had the highest survivability but the differences between 3083-O and 3083-T were noteworthy. When grown in the absence of glycerol, cells of the MDO-12 series survived less well in normal saline than when they were grown in glycerol, but the protective effect of the capsule now became evident. One may conclude that both PHB levels and amount of capsule can contribute to survival under adverse conditions. In contrast to the recent observations of Ravel et al. (1995) in 'artificial seawater', no reversion to viability 
(a)



(b)

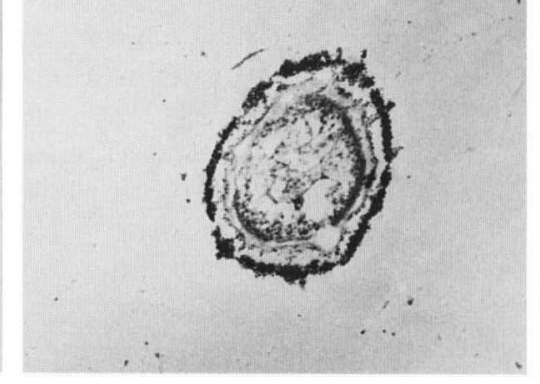

(c)

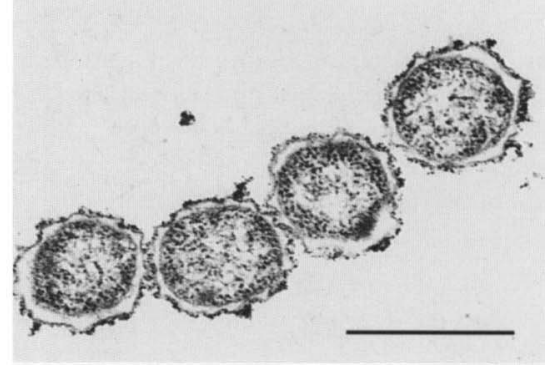

Fig. 4. Polycationic-ferritin-stained transmission electron microscopy of: (a) MDO-12-C; (b) MDO-12-B; and (c) MDO-12-A. Bar, $0.5 \mu \mathrm{m}$.

Table 4. PHB content of $V$. cholerae 01 and 0139 strains of varying opacity (data from Table 3)

\begin{tabular}{|crrrr|}
\hline \multicolumn{2}{|c}{ Opacity } & & \multicolumn{2}{c|}{ PHB $\dagger$} \\
\cline { 5 - 6 } \cline { 5 - 5 } Range* $^{*}$ & Mean \pm SE & & Range & Mean \pm SE \\
\hline $1-5(12)$ & $3 \cdot 5 \pm 0 \cdot 4$ & & $1 \cdot 8-9 \cdot 3$ & $2 \cdot 9 \pm 0.6$ \\
$>5-10(22)$ & $6 \cdot 6 \pm 0 \cdot 3$ & & $14 \cdot 8-47 \cdot 2$ & $26.4 \pm 1 \cdot 7$ \\
\hline
\end{tabular}

*Number of strains examined shown in parentheses.

was observed when the temperature was shifted up from $4{ }^{\circ} \mathrm{C}$ to $30^{\circ} \mathrm{C}$.

\section{DISCUSSION}

Faced by many previous observations of colonial heterogeneity which, in some instances, were associated with such important phenotypic properties as virulence for chicken embryos (Lankford, 1960; Gardner et al., 1964), haemolysis in the O1 El Tor biotype (Finkelstein, 1966), toxigenicity and virulence (Holmes et al., 1975), and, most recently, capsulation in the new 0139 serovar (Johnson et al., 1994; Weintraub et al., 1994), we decided to attempt to define the reason(s) for opacity and translucency and the potential value of such variations to the vibrios. The present findings suggest that colony opacity variations among the choleragenic vibrios are multifactorial. It should be noted that freshly isolated and carefully preserved strains are considerably more homogeneous than stock cultures; i.e. we may conclude that a great deal of the heterogeneity we have observed occurs subsequent to primary isolation.

Our first step was to develop a reproducible method of quantifying opacity. This was accomplished by defining arbitrarily a set of reference opacity standard strains with which to compare unknown cultures on the same Petri dish using transmitted oblique illumination and a stereoscopic microscope. With this technique we could reliably characterize, in opacity units (OUs), the range of variation observed in freshly isolated strains as well as the remarkable heterogeneity found in many stock
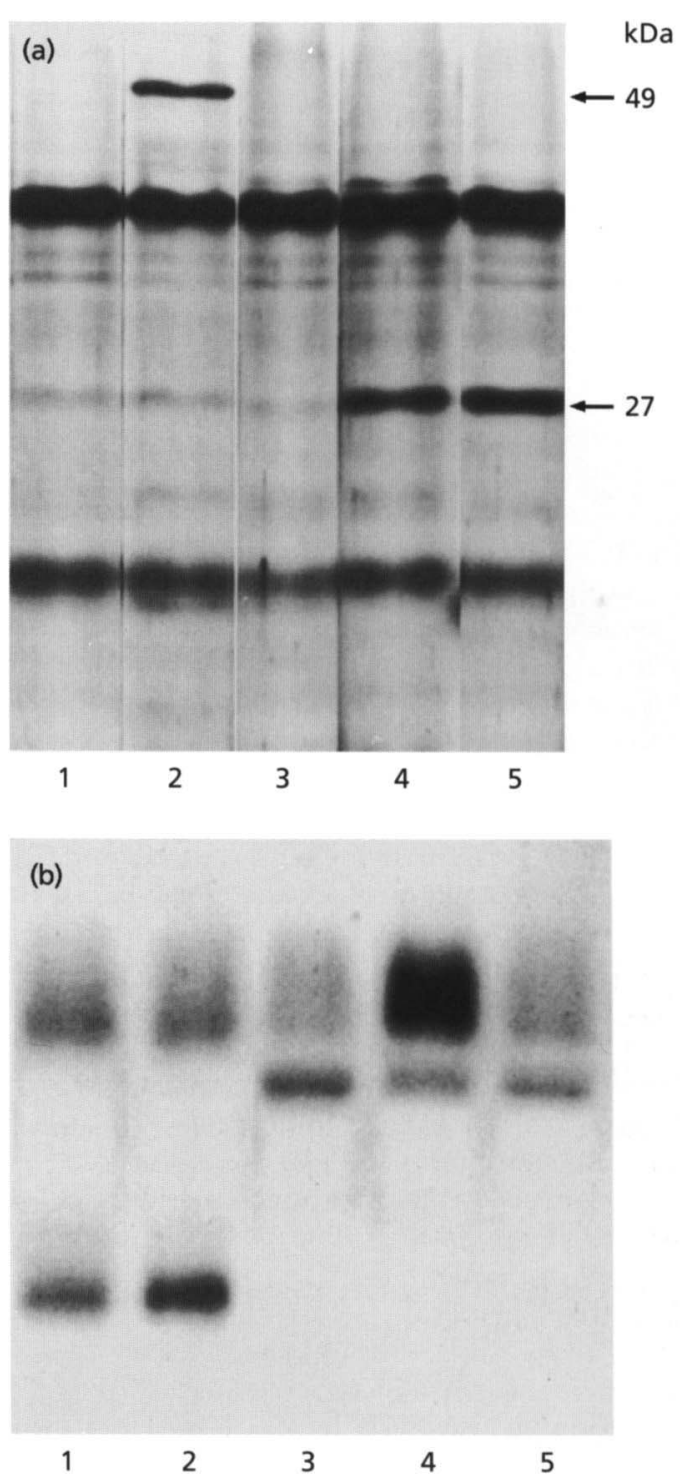

Fig. 5. SDS-PAGE of outer-membrane proteins (a) and LPS (b) of: (a) strains 3083-O, 3083-T, MDO-12-C, MDO-12-B and MDO12-A (lanes 1-5, respectively); and (b) MDO-12-A, MDO-12-B, MDO-12-C, 3083-T and 3083-O (lanes 1-5 respectively). Panel (b) has been digitally processed to enhance contrast. 
Table 5. Survival of spontaneous variants of $V$. cholerae in normal saline

Bacteria were cultivated on medium containing $0.5 \%$ glycerol $(+)$ or not $(-)$, diluted to approximately $10^{6}$ viable cells per $\mathrm{ml}$ of normal saline, incubated for $24 \mathrm{~h}$, and dilution-plated. Results are shown as percentage survival (mean of duplicate determinations; $\mathrm{NG}$, no growth from $10 \mu \mathrm{l}$ ).

\begin{tabular}{|c|c|c|c|c|}
\hline Strain & Glycerol & $4^{\circ} \mathrm{C}$ & $25^{\circ} \mathrm{C}$ & $37^{\circ} \mathrm{C}$ \\
\hline \multirow[t]{2}{*}{ MDO-12-A } & - & NG & NG & NG \\
\hline & + & $2 \cdot 0$ & $31 \cdot 0$ & $27 \cdot 0$ \\
\hline \multirow[t]{2}{*}{$-B$} & - & $0 \cdot 3$ & $3 \cdot 5$ & $3 \cdot 0$ \\
\hline & + & $5 \cdot 0$ & $41 \cdot 0$ & $39 \cdot 0$ \\
\hline \multirow[t]{2}{*}{$-\mathrm{C}$} & - & $11 \cdot 0$ & $64 \cdot 6$ & $61 \cdot 0$ \\
\hline & + & $55 \cdot 0$ & $95 \cdot 0$ & $93 \cdot 0$ \\
\hline \multirow{2}{*}{$3083-\mathrm{T}$} & - & 0.2 & $0 \cdot 6$ & 0.003 \\
\hline & + & $0 \cdot 8$ & $3 \cdot 0$ & $3 \cdot 0$ \\
\hline \multirow{2}{*}{$-\mathrm{O}$} & - & 0.05 & $1 \cdot 2$ & NG \\
\hline & + & $4 \cdot 0$ & $33 \cdot 0$ & $31 \cdot 0$ \\
\hline
\end{tabular}

cultures. The apparent discrepancy between previous observations on colonial opacity (Lankford, 1960; Finkelstein \& Gomez, 1963; Finkelstein \& Punyashthiti, 1967) resided in the culture media used by the different investigators. The addition of glycerol tended to increase colonial opacity. Electron microscopic observations revealed that this also led to the production of intracellular inclusion bodies. Some of these stained with malachite green, which had been reported (Sun et al., 1994) to selectively stain PHB. This was confirmed by biochemical assay which, like the electron microscopic observations, also showed that the PHB granules were consumed under crowded conditions and with ageing of the culture. The levels of PHB produced on glycerol medium strongly correlated with the opacity of the culture observed in the presence or absence of glycerol. In fact, examination of an extensive series of strains and colonial variants revealed a significant difference in $\mathrm{PHB}$ levels between strains with $>5$ OUs and those with 5 OUs or less. The reason why glycerol enhances opacity is probably because of its place in intermediary metabolism which leads - through pyruvate, acetyl-CoA, acetoacetyl-CoA to 3-hydroxybutyryl-CoA and, by the enzyme PHB synthase - to PHB (Leaf et al., 1996). PHB may also serve as a carbonaceous energy storage mechanism (Leaf et al., 1996; Östling et al., 1993). Actually in subsequent tests, pyruvate was even more effective than glycerol in enhancing opacity (D. K. Sengupta and others, unpublished). Why this should reflect opacity as seen in the absence of glycerol (and correspondingly low PHB levels) is not yet clear and remains an important question for further investigation. Perhaps translucency, in the presence or absence of glycerol, could be coupled to a defect in the ability to synthesize PHB.

Others have concluded that encapsulation is the primary determinant of opacity of V. cholerae O139 (Johnson et al., 1994; Weintraub et al., 1994). The present findings are consistent with the hypothesis that opacity is associated with encapsulation in $\mathrm{O} 139$ but indicates that other factors may also be involved. Studies with the MDO-12 series of variants indicate that although the degree of encapsulation varies in the appropriate order of opacity, the more translucent variants also express a characteristic $27 \mathrm{kDa}$ outer-membrane protein, they had a different LOS structure when compared with the opaque variant, and they expressed different glycolytic pathways (MR/VP). Nevertheless, both the most opaque and the most translucent variants were equally virulent for infant rabbits. We have reported separately (Sengupta et al., 1996) that antibody against the 0139 capsule is protective in infant mice. Although the capsule may contribute to virulence it may not be completely essential (D. K. Sengupta and others, unpublished). Interestingly, a TnphoA insertional mutant of MDO-12$\mathrm{C}$, with no capsular polysaccharide (detectable by Western blotting with specific anticapsular serum), was more opaque than some encapsulated variants, and it was found to cause fluid accumulation in suckling mice although it adhered to the intestinal mucosa 100-fold less effectively than parent MDO-12-C (D. K. Sengupta and others, unpublished).

It is clear from the present work that the ability to produce PHB is proportional to opacity in freshly isolated and carefully preserved cultures whereas in older stock cultures and variants the relationship is less proportional but still significant. What benefit is it to the cholera vibrios to vary their PHB content? PHB is regarded as a carbon and energy reserve material in bacteria (Page \& Knosp, 1989; Anderson \& Dawes, 1990) and it enhances survival of some bacteria during nutrient starvation. The present study suggests that this may be the case in V. cholerae. Vibrios with higher PHB content were better able to survive nutrient deprivation. PHB levels fell with age of the culture and the degree of crowding, as did the content of electron-translucent inclusions of strain MDO-12-C. Further studies are needed to identify these electron-translucent granules. Similar inclusions were found in V. harveyi cells stained with malachite green (Sun et al., 1994). Survivability of O139 strains may also be promoted by the degree of encapsulation.

For most of the century since the discovery of cholera vibrios by Koch, human beings were considered to be their sole reservoir in nature. However, older as well as more recent studies have shown that they may persist, for varying periods, in brackish estuaries in choleraendemic areas, perhaps in association with plankton and shellfish (Pollitzer, 1959, pp. 546-547, 858-860; Colwell \& Spira, 1992; Glass \& Black, 1992; Blake, 1994; Colwell \& Huq, 1994; Kaysner \& Hill, 1994; Mintz et al., 1994; Tauxe et al., 1994), which can serve as vehicles of infection. Recognizing that it is extremely difficult to establish whether they are of human or environmental origin, it would be interesting indeed to determine whether persistence of choleragenic vibrios in the environment is associated with opacity and PHB 
content. Is it possible that the demonstrated capability of variation of $V$. cholerae strains, with regard to opacity, PHB content, capsulation, OMPs, LPS, and glycolytic pathway, provides mechanisms of assuring their survival outside the warm and nutrious milieu of the human gut? In addition to simply serving as a carbon and energy reserve, PHB turnover has been demonstrated to direct the formation of dormant cells (Reusch \& Sadoff, 1981). Colwell and her associates (Colwell \& Spira, 1992; Colwell \& Huq, 1994) have implied that true cholera vibrios can exist autochthonously in brackish water and estuarine systems in a viable but nonculturable state', potentially to emerge with pathogenic and epidemic potential. It would be of interest to evaluate whether PHB is involved.

Using $\operatorname{Tn} p h o A$ insertional mutagenesis, we are trying to ascertain which properties - PHB, capsule, outer-membrane proteins, LOS, and/or glycolytic pathway - are most directly responsible for - or associated with opacity/translucency. Preliminary results thus far suggest that PHB content, translucency-associated outer-membrane proteins and glycolytic pathway are constant markers and the other properties may be variable (D. K. Sengupta and others, unpublished). It will be important to apply molecular genetics to determine whether these are independent variables defined by multiple separate genetic pathways or whether they are the pleiotropic result of single genetic regulatory events. Studies on effects of other physiological manipulations, such as nutritional alterations and growth temperature, on opacity/translucency may also be revealing.

\section{ACKNOWLEDGEMENTS}

This work was supported in part by US Public Health Service grant AI17312 to R.A.F. from the National Institute of Allergy and Infectious Diseases and by a grant from the Natural Sciences and Engineering Research Council of Canada to W.J.P. We are appreciative of the excellent technical assistance of Jan Manchak in the Canadian laboratory and that of Paul A. Brugmann and William Atherton in Missouri. Louise Thai performed the initial API testing which revealed the methyl red-VP variations of colonial variants of strain MDO-12 and Jill Cunningham provided general technical support. R. Clinton Fuller, L. J. R. Foster, E. J. Knee and A. Tehrani performed preliminary analysis of PHB content and provided helpful suggestions. Edward A. Meighen provided a Vibrio harveyi strain for preliminary tests of the malachite green procedure and we appreciate, also, the generosity of G. Balakrish Nair, M. John Albert and Yoshifumi Takeda for providing $\mathrm{O} 139$ strains and an antiserum used in this study. We appreciate the constructive criticism of the manuscript by Dr Jorge A. Benitez.

\section{REFERENCES}

Albert, M. J. (1994). Vibrio cholerae O139 Bengal. J Clin Microbiol 32, 2345-2349.

Anderson, A. J. \& Dawes, E. A. (1990). Occurrence, metabolism, metabolic role, and industrial uses of bacterial polyhydroxyalkanoates. Microbiol Rev 54, 450-472.
Blake, P. A. (1994). Endemic cholera in Australia and the United States. In Vibrio cholerae and Cholera: Molecular to Global Perspectives, pp. 309-319. Edited by I. K. Wachsmuth, P. A. Blake \& O. Olsvik. Washington, DC: American Society for Microbiology.

Braun, W. (1953). Bacterial Genetics, pp. 106-107. Philadelphia: W. B. Saunders.

Colwell, R. R. \& Huq, A. (1994). Vibrios in the environment: viable but nonculturable Vibrio cholerae. In Vibrio cholerae and Cholera: Molecular to Global Perspectives, pp. 117-133. Edited by I. K. Wachsmuth, P. A. Blake \& O. Olsvik. Washington, DC: American Society for Microbiology.

Colwell, R. R. \& Spira, W. M. (1992). The ecology of Vibrio cholerae. In Cholera, pp. 107-127. Edited by D. Barua \& W. B. Greenough III. New York: Plenum Medical Book Co.

Filip, C., Fletcher, G., Wulff, J. L. \& Earhart, C. F. (1973). Solubilization of the cytoplasmic membrane of Escherichia coli by the ionic detergent sodium-lauryl sarcosinate. J Bacteriol 115, 717-722.

Finkelstein, R. A. (1962). Vibriocidal antibody inhibition (VAI) analysis: a technique for the identification of the predominant vibriocidal antibodies in serum and for the recognition and identification of Vibrio cholerae antigens. JImmunol 89, 264-271.

Finkelstein, R. A. (1966). Preselection of hemolytic variants of El Tor vibrios. J Bacteriol 92, 513-514.

Finkelstein, R. A. \& Gomez, C. Z. (1963). Comparison of methods for the rapid recognition of cholera vibrios. Bull WHO 28, 327-332.

Finkelstein, R. A. \& Punyashthiti, K. (1967). Colonial recognition, a 'new' approach for rapid enteric bacteriology. J Bacteriol 93, 1897-1905.

Finkelstein, R. A., Boesman-Finkelstein, M., Chang, Y. \& Häse, C. C. (1992). Vibrio cholerae hemagglutinin/protease, colonial variation, virulence and detachment. Infect Immun 60, 472-478.

Gardner, E. W., Lyles, S. T. \& Lankford, C. E. (1964). A comparison of virulence of Vibrio cholerae strains for the embryonated egg. $J$ Infect Dis 114, 412-416.

Glass, R. I. \& Black, R. E. (1992). The epidemiology of cholera. In Cholera, pp. 129-154. Edited by D. Barua \& W. B. Greenough III. New York: Plenum Medical Book Co.

Henry, B. S. (1933). Dissociation in the genus Brucella. J Infect Dis 52, 374-402.

Holmes, K. K., Vasil, M. L. \& Finkelstein, R. A. (1975). Studies on toxinogenesis in Vibrio cholerae. III. Characterization of nontoxinogenic mutants in vitro and in experimental animals. J Clin Invest 55, 551-560.

Hood, M. A., Guckert, J. B., White, D. C. \& Deck, F. (1986). Effect of nutrient deprivation on lipid, carbohydrate, DNA, RNA, and protein levels in Vibrio cholerae. Appl Environ Microbiol 52, 788-793.

Johnson, J. A., Panigrahi, P. \& Morris, J. G., Jr (1992). Non-O1 Vibrio cholerae NRT36S produces a polysaccharide capsule that determines colony morphology, serum resistance, and virulence in mice. Infect Immun 60, 864-869.

Johnson, J. A., Salles, C. A., Panigrahi, P., Albert, M. J., Wright, A. C., Johnson, R. J. \& Morris, J. G., Jr (1994). Vibrio cholerae O139 synonym Bengal is closely related to Vibrio cholerae $\mathrm{El}$ Tor but has important differences. Infect Immun 62, 2108-2110.

Karr, D. B., Waters, J. K. \& Emerich, D. W. (1983). Analysis of poly- $\beta$-hydroxybutyrate in Rhizobium japonicum bacteroids by ion-inclusion high-pressure liquid chromatography and UV detection. Appl Environmental Microbiol 46, 1339-1344. 
Kaysner, C. A. \& Hill, W. E. (1994). Toxigenic Vibrio cholerae O1 in food and water. In Vibrio cholerae and Cholera: Molecular to Global Perspectives, pp. 27-39. Edited by I. K. Wachsmuth, P. A. Blake \& O. Olsvik. Washington, DC: American Society for Microbiology.

Kimura, A. \& Hansen, E. J. (1986). Antigenic and phenotypic variations of Haemophilus influenzae type b lipopolysaccharide and their relationship to virulence. Infect Immun 51, 69-79.

Kushnaryov, V. M., Dunne, W. M., Jr \& Buckmire, F. L. A. (1980). Electron microscopy of malachite green-glutaraldehyde fixed bacteria. Stain Technol 54, 331-336.

Laemmli, U. K. (1970). Cleavage of structural proteins during the assembly of the head of bacteriophage T4. Nature 227, 680-685.

Leaf, T. A., Peterson, M. S., Stoup, S. K., Somers, D. \& Srienc, F. (1996). Saccharomyces cerevisiae expressing bacterial polyhydroxybutyrate synthase produces poly-3-hydroxybutyrate. Microbiology 142, 1169-1180.

Lankford, C. E. (1960). Factors of virulence of Vibrio cholerae. Ann N Y Acad Sci 88, 1203-1212.

Markwell, M. A. K., Haas, S. M., Bieber, L. L. \& Tolbert, N. E. (1978). A modification of the Lowry procedure to simplify protein determination in membrane and lipoprotein samples. Anal Biochem 87, 206-210.

Mills, J. A., Venkatesan, M. M., Baron, L. S. \& Buysse, J. M. (1992). Spontaneous insertion of an IS1-like element into the virF gene is responsible for avirulence in opaque colonial variants of Shigella flexneri 2a. Infect Immun 60, 175-182.

Mintz, E. D., Popovic, T. \& Blake, P. A. (1994). Transmission of Vibrio cholerae. In Vibrio cholerae and Cholera: Molecular to Global Perspectives, pp. 345-356. Edited by I. K. Wachsmuth, P. A. Blake \& O. Olsvik. Washington, DC: American Society for Microbiology.

Oakley, B. R., Kirsch, D. R. \& Morris, N. R. (1980). A simplified ultrasensitive silver stain for detecting proteins in polyacrylamide gels. Anal Biochem 105, 361-363.

Östling, J., Holmquist, L., Flärdh, K., Svenblad, B., Jouper-Jaan, Å. \& Kjelleberg, S. (1993). Starvation and Recovery of Vibrio. In Starvation in Bacteria, pp. 103-127. Edited by S. Kjelleberg. New York \& London: Plenum Press.

Page, W. J., Manchak, J. \& Rudy, B. (1992). Formation of poly(hydroxybutyrate-co-hydroxyvalerate) by Azotobacter vinelandii UWD. Appl Environ Microbiol 58, 2866-2873.

Page, W. J. \& Knosp, O. (1989). Hyperproduction of poly- $\beta$ hydroxybutyrate during exponential growth of Azotobacter vinelandii U.WD. Appl Environ Microbiol 55, 1334-1339.

Pollitzer, R. (1959). Cholera. Geneva, Switzerland: World Health Organization.

Poolman, J. T., Hopman, T. P. \& Zanen, H. C. (1985). Colony variants of Neisseria meningitidis strain 2996 (B:2b:P1.2): influence of class-5 outer membrane proteins and lipopolysaccharides. J. Med Microbiol 19, 203-209.

Ravel, J., Knight, I. T., Monahan, C. E., Hill, R. T. \& Colwell, R. R. (1995). Temperature-induced recovery of Vibrio cholerae from the viable but non-culturable state: growth or resuscitation? Microbiology 141, 377-383.

Reusch, R. N. \& Sadoff, H. L. (1981). Lipid metabolism during encystment of Azotobacter vinelandii. J Bacteriol 145, 889-895.
Sengupta, D. K., Boesman-Finkelstein, M. \& Finkelstein, R. A. (1996). Antibody against the capsule of Vibrio cholerae 0139 protects against experimental challenge. Infect Immun 64, 343-345.

Shimada, T., Nair, G. B., Deb, B. C., Albert, M. J., Sack, R. B. \& Takeda, Y. (1993). Outbreak of Vibrio cholerae non-O1 in India and Bangladesh. Lancet 341, 1346-1347.

Sun, W., Cao, J.-G., Teng, K. \& Meighen, E. A. (1994). Biosynthesis of poly- $\beta$-hydroxybutyrate in the luminescent bacterium, Vibrio harveyi, and regulation by the $\ln x$ autoinducer, $N-(3-$ hydroxybutanoyl)homoserine lactone. J Biol Chem 269, 20785-20790.

Swanson, J., Belland, R. J. \& Hill, S. A. (1992). Neisserial surface variation: how and why? Curr Opin Genet Dev 2, 805-811.

Tamura, T., Fujino, T., Kondo, M. \& Kotani, S. (1968). Occurrence of poly- $\beta$-hydroxybutyric acid inclusions in Vibrio parabaemolyticus A55. Biken J 11, 225-234.

Tauxe, R., Seminario, L., Tapia, R. \& Libel, M. (1994). The Latin American epidemic. In Vibrio cholerae and Cholera: Molecular to Global Perspectives, pp. 321-344. Edited by I. K. Wachsmuth, P. A. Blake \& O. Olsvik. Washington, DC: American Society for Microbiology.

Tsai, C. M. \& Frasch, C. E. (1982). A sensitive silver stain for detecting lipopolysaccharides in polyacrylamide gels. Anal Biochem 119, 115-119.

Waldor, M. K., Colwell, R. \& Mekalanos, J. J. (1994). The Vibrio cholerae $\mathrm{O} 139$ serogroup antigen includes an $\mathrm{O}$-antigen capsule and lipopolysaccharide virulence determinants. Proc Natl Acad Sci USA 91, 11388-11392.

Weintraub, A., Widmalm, G., Jansson, P.-E., Jansson, M., Hultenby, K. \& Albert, M. J. (1994). Vibrio cholerae O139 Bengal possesses a capsular polysaccharide which may confer increased virulence. Microb Pathog 16, 235-241.

Weiser, J. N. (1993). Relationship between colony morphology and the life cycle of Haemophilus influenzae: the contribution of lipopolysaccharide phase variation to pathogenesis. J Infect Dis 168, 672-680.

Weiser, J. N., Austrian, R., Sreenivasan, P. K. \& Masure, H. R. (1994). Phase variation in pneumococcal opacity: relationship between colonial morphology and nasopharyngeal colonization. Infect Immun 62, 2582-2589.

Weiser, J. N., Chong, S. T. H., Greenbey, D. \& Fong, W. (1995). Identification and characterization of a cell envelope protein of Haemophilus influenzae contributing to phase variation in colony opacity and nasopharyngeal colonization. Mol Microbiol 17, 555-564.

Wise, K. S., Yogev, D. \& Rosengarten, R. (1992). Antigenic variation. In Mycoplasmas: Molecular Biology and Pathogenesis, pp. 473-490. Edited by J. Maniloff, R. N. McElhaney, L. R. Finch \& J. B. Baseman. Washington, DC: American Society for Microbiology.

Yoshida, S.-I., Ogawa, M. \& Mizuguchi, Y. (1985). Relation of capsular materials and colony opacity to virulence of Vibrio vulnificus. Infect Immun 47, 446-451.

Received 8 July 1996; revised 16 September 1996; accepted 30 September 1996. 